\title{
FRIDA KAHLO, PINTORA DE SU VIDA
}

\section{Lindy Arriaga*}

Las casas en donde compartieron la vida Frida Kahlo y Diego Rivera en México son el puente que nos remonta y retrotrae a esos convulsivos años de la primera mitad del siglo en que ellos desarrollaron su arte y se convirtieron en eje de la vida intelectual mexicana. Tanto la casa de San Ángel como la casa azul de Coyoacán nos hacen sentir vigente la energía de sus moradores. En la de Diego sus caballetes, su arte precolombino, sus muestras artesanales, su culto a la muerte. En la de Frida la encantadora cocina, sus trajes y joyas pero, sobretodo, esa impresionante muestra de milagros santeros, cuadritos diminutos pintados 0 encargados a artistas y artesanos como exvotos después de una curación o milagro "palpable".

Frida Kahlo, hija de emigrante alemán y mexicana, nació en julio de 1907. Su padre fue el primer fotógrafo oficial del patrimonio cultural de México y Frida, la tercera de cuatro hermanas, la preferida. De niña le diagnosticaron poliomielitis de la cual le quedó como secuela un pie ligeramente atrofiado y una piema un poco más corta y delgada, por lo cual se vio obligada a usar botas ortopédicas. A los 18 años sufrió un aparatoso accidente cuando el bus en que viajaba chocó contra un tren. Con múltiples fracturas, entre ellas las de la tercera y cuarta vértebras lumbares, herida profunda en el abdomen, pues una barra de hierro le penetró por la cadera izquierda y le salió por la vagina, causándole grandes destrozos y peritonitis, Frida luchó por su vida durante tres largos meses en el hospital de la Cruz Roja. En su casa debió guardar reposo absoluto y un mes más tarde armaron sobre su cuerpo el primer corsé de yeso que debería usar durante nueve meses.

Frida se vio obligada a abandonar sus estudios de medicina, que había iniciado en la Preparatoria y, forzada por la quietud, a dedicarse a leer y a escribir, a pasar a papel la angustia que la consumía, sin saber cómo lograría levantarse de esa cama y afrontar la vida. Cuatro meses después del accidente Frida volvió a caminar. Primero en su casa y en el jardín, luego en el Zócalo, en el corazón de la ciudad, y sólo allí pudo sentir que todavía vi vía.

Casi un año después del accidente Frida recayó y fue nuevamente inmovilizada en cama. Leía, escribía cartas y maldecía a los médicos, a quienes trataba de ladrones. A Matilde, una de sus hermanas, se le ocurrió cambiar la cama de Frida en una con baldaquín y sujetar al cielo de ella un espejo. Desde ese momento su imagen se convirtió en el mejor modelo. Repitió su rostro una y mil veces. Aprendió a encontrar en él diversas expresiones y matices. Su padre, después, le trajo tubos de pintura y agregó el color.

\footnotetext{
*Profesora de Latín Universidad Pedagógica Nacional. 
Surgieron así sus primeros auto-retratos. Después pintó a sus amigos. Dudaba mucho. Rompía las telas que no la satisfacían. Un corsé sucedía a otro. El tiempo transcurría y ella, casi restablecida, se vio obligada a buscar trabajo. Por sus amigos conoció a Julio Antonio Mella, comunista cubano exiliado en México y a su mujer, Tina Modoti, de quien fue muy amiga. En 1929 Frida se afilió al partido comunista, en el que militaban muchos de sus amigos. Fue en este ambiente de artistas y bohemios revolucionarios donde Frida conoció al hombre que iba a marcar su vida: Diego Rivera.

Diego era en esos momentos el hombre de moda. Grande, gordo, feo, con ojos saltones, nariz chata y labios gruesos, su exuberancia se manifes taba no sólo en el físico o en su modo de atraer sobre él la atención, sino en su arte. A los veinte años había recibido una beca para estudiar en la Escuela de Bellas Artes de Madrid, en donde se destacó por la dedicación al trabajo pero, también, por su figura y osadía. Fue a Holanda, Bélgica, Inglaterra y finalmente se instaló en París en donde vivió por casi diez años. Luego Italia. Cuando regresó a México habían transcurrido catorce años. Sus exposiciones en París no tuvieron mayor éxito, aunque recibió el reconocimiento de algunos intelectuales importantes como Apollinaire, quien fue su amigo personal y de quien Diego recitaba poemas enteros en un francés algo extraño.

José Clemente Orozco, David Alfaro Siqueiros y Diego Rivera, los tres de regreso del extranjero, se repartieron el muralismo mexicano oficial en los años veinte, pero fue Diego Rivera quien quiso llegar directamente al pueblo exaltando sus ancestros y rindiendo culto al proceso revolucionario del país. En 1922 Diego ingresó al Partido Comunista. Al año siguiente, inició los 124 murales de la Secretaría de Educación, una de sus obras más importantes, en cuya ejecución demoró cuatro años. En 1927 Diego recibió una invitación oficial para ir a la Unión Soviética a pintar un mural en el edificio del Ejército Rojo.

En París, Diego había vivido con una rusa, Angelina Beloff, a quien dejó cuando regresó a México. En Jalis co encontró a Guadalupe Marín, con quien convivió por siete años y tuvo dos hijas. Tenía fama de mujeriego y de ser amante de sus modelos, pero ese encanto tan escandaloso del pintor y la aureola que lo rodeaba fue lo que atrajo a Frida. La pareja contrastaba: Diego era monumental, Frida menuda. Veinte años de diferencia en edad y muchos de experiencia. Frida había madurado con el dolor y su personalidad se destacaba ya en el medio. Cuando conoció a Diego abandonó los vestidos de hombre y los overoles de obrero y empezó a usar vestidos típicos mexicanos de faldas largas, enaguas de puntillas, peinados con cintas, joyas pesadas y, sobre los hombros, siempre un rebozo. Se casaron en el Ayuntamiento de Coyoacán, el 21 de agos to de 1929.

Diego trabajaba intensamente, teminaba los murales en la Secretaría de Educación e iniciaba otros en la Secretaría de Salud. También le habían solicitado unos en el Palacio Nacional, pero empezó a recibir críticas del Partido por sus relaciones con el gobiemo. El día de su expulsión se autoacusó de "colaborador con el gobierno pequeño-burgués de México". Entre tanto, él y Frida se instalaron 
en la casa de los Kahlo en Coyoacán. Frida quedó embarazada, pero tres meses más tarde tuvieron que provocarle un aborto; le habían diagnosticado una malformación pélvica que impediría que el embarazo llegara a su témino.

En el otoño de 1930 Diego Rivera recibió la propuesta de ejecutar una serie de murales en Estados Unidos, en el San Francisco Art Institute y en el Luncheon Club de la Bolsa de valores de la misma ciudad. La invitación despertó en México fuertes críticas, pero Diego y Frida viajaron en Noviembre. No tardaron en convenirse en centro de atracción y de invitaciones y poco a poco se fueron acostumbrando a su vida en el país. Más tarde sería Nueva York, cuando la consejera crítica de los Rockefeller le solicitó a Diego una exposición retrospectiva. Diego se entregó al trabajo, pues tenía que reconstruir 150 obras partiendo de simples esbozos o fragmentos de murales. $Y$ volvieron a ser centro de fiestas y cenas en donde Frida lucía sus encantos y excentricidades y Diego era celebrado como un genio. La exposición fue un éxito.

El pintor se sentía halagado en Estados Unidos y le pagaban en dólares. Repartía sus noches entre fiestas burguesas y reuniones con sus amigos artistas del Greenwich Village, con quienes compartía su paga. Frida, entre tanto, cada vez más sola volvía a pintar y agudizaba un humor sarcástico que llegó a caracterizarla en las fiestas con su marido. Vino luego el ofrecimiento de un mural en el Detroit Institute of Arts, financiado por Edsel Ford. Frida queda nuevamente embarazada y sufre esta vez un doloroso aborto espontáneo. Su matemidad frus trada se convierte en tema de sus cuadros.

Por invitación de los Rockefeller regresan a Nueva York donde Rivera inicia el discutido mural del Rockefeller Center, que se vio interrumpido cuando plasmó en él la cabeza de Lenin. En 1934 deciden finalmente regresar a México.

Se instalaron, entonces, en la casa de San Ángel y volvieron a llevar una vida animada rodeados de amigos. Diego tenía que teminar los murales del Palacio Nacional y rehacer el mural del Rockefeller Center en el palacio de Bellas Artes. Frida nuevamente recae, sufre la primera operación en el pié derecho y se somete a un tercer aborto provocado. Diego, siempre rodeado por mujeres, vuelve a sus andanzas amorosas. Su esposa decide volver a Nueva York. Esta es la época en que las infidelidades son mutuas. Frida se enamora del escultor Isamu Naguchi, pero Rivera pone fin al romance. Muchas de las amantes de Rivera se convierten después en amigas de Frida, quien encuentra así un medio para controlar las relaciones de su marido.

En el año 37 Diego interviene ante el gobiemo para que le concedan asilo político a León y a Natalia Trotski, quienes desde 1929 habían pasado como refugiados por Turquía, Noruega y Francia. Frida los aloja en su casa de Coyoacán en donde se instalan con secretarios, servidores y camaradas asignados a diferentes oficios. Como una comisión internacional investigaba las acusaciones contra Trotski y su hijo en el proceso de Mos aú, todas las actividades se organizaron en la casa con gran cautela. En febrero del 38 les llega la noticia de la muerte de Liova Trotski, 
cuando se acentúan en México las diferencias entre trotskistas y stalinistas. En abril se anunció la llegada de Andre Breton y su esposa a México, quienes vivieron más tarde en casa de Frida y Diego. Fue Breton quien clasificó la obra de Frida como surrealista, mientras Diego la denominaba "realismo monumental".

La obra de Frida Kahlo es eminentemente biográfica. En cuadros de pequeño formato, que sólo excepcionalmente rebasan los 50 centímetros, plasmó Frida los hechos más importantes de su vida marcados, en su gran mayoría, por la tragedia yel dolor. Diego la describió así:

"Varios críticos de diversos país es han encontrado que la pintura de Frida Kahlo es la más profunda y populamente mexicana del tiempo actual. Yo estoy de acuerdo con esto. En México hay una pintura poco conocida, humilde en sus dimensiones físicas y pretensiones de contenido. Son pequeñas láminas de metal o madera sobre las que se ha pintado el milagro con que algún santo, virgen o Dios favorece a una o varias personas, y para dejar testimonio en el santuario corres pondiente se pintan estos pequeños cuadros (...).

Estos retablos foman indudablemente la expresión pictórica más genuina en la base del pueblo mexicano (...) Entre los pintores cotizados el único que se liga estrechamente con es ta pura producción popular es Frida Kahlo (...). Aunque su pintura no se extienda sobre las grandes superficies de nuestros murales, por su contenido en intensidad y profundidad, más que el equivalente de nuestra cantidad y calidad, Frida Kahlo es el más grande de los pintores mexicanos (...)",

Durante el otoño de 1938 Frida fue invitada a exponer 25 cuadros en la galería Julien Levy en Nueva York. La exposición a la que asistieron grandes personalidades fue todo un éxito y recibió muy buenas críticas. André Breton abría el catálogo con su prefacio sobre la obra de Frida. De Nueva York viajó la artista a París en donde, después de algunos inconvenientes, pudo organizar una exposición y relacionarse con artistas como Paul Eluard, Yves Tanguy, Max Ernst y Marcel Duchamp. El museo del Louvre le compró uno de sus cuadros. Picasso se referiría a Frida en una carta a Rivera diciendo: "Ni tú, ni Derain, ni yo sabemos pintar caras como las de Frida Ka hlo"”.

En marzo Frida sale de París y regresa a Nueva York. En el barco empieza su conocido cuadro El suicidio de Dorothy Halle, en el cual la sangre salpica hasta el marco del cuadro. De Nueva York nuevamente a México a donde regresa temerosa de su reencuentro con Diego. En México la situación no era fácil; Trotski estaba a punto de mudarse de la casa de los Kahlo, después de su rompimiento con Diego. Este, a su vez, vivía uno tras otro sus escándalos amorosos: la húngara Irene Bohus, la actriz Paulette Goddard... Frida se entrega de nuevo al

\footnotetext{
${ }^{1}$ bol, Raquel. Frida Kalho, una vida abierta. Biblioteca de las decisiones. México: Ed. Casis, 1985, pp. 95-96.

2 Tibol, Raquel. Op. cit., p. 95.
} 
trabajo y regresa a la casa azul. Empieza a pintar Las dos Fridas, un cuadro que por su tamaño, más de 1.60 por otro tanto, y por el tema, su imagen doble, la una ves tida de tehuana, la otra con blusa de cuello alto de encaje y el corazón abierto, sangrando, se sale de lo acostumbrado; aunque varía la expresión las dos miran con seriedad al frente. La casa de Coyoacán se llena de animales has ta parecer un pequeño zoológico: un venado, monos, palomas, cotorras, perros. Y Frida y su soledad, pues Diego en la casa de San Ángel, poco la visita. A finales de septiembre Frida y Diego, de común acuerdo, piden el divorcio.

Los años 39 y 40 marcan un período muy fructífero para Frida quien se dedica a su arte: Las dos Fridas, Autorretrato Con mono, Autorretrato de pelona, Autorretrato con collar de espinas y colibrí. En la galería de arte mexicano que organizó la Exposición Internacional del Surrealismo, Breton, César Moro y Paalen lograron reunir grandes personalidades, entre ellas Giacometti, Picasso, Yves Tanguy, Kandinsky, Paul Klee, Salvador Dalí. Frida participó con Las dos Fridas y La nieva herida $\mathrm{y}$, aunque la exposición fue clasificada de ecléctica y desordenada, fue todo un acontecimiento en México.

En esta época Frida bebe y pasa nuevas temporadas en el hospital. Vuelve a Nueva York mientras Diego trabaja en San Francisco. Finalmente deciden casarse por segunda vez y regresan a México para instalarse en la casa azul de Coyoacán. La salud de Frida es cada vezpeor; se ve obligada a llevar un corsé de acero y a recurrir a la morfina para controlar el dolor de la espalda.

En 1942 la Escuela de Talla Directa de la Secretaría de Educación Pública fue convertida en Escuela de Pintura y Escultura. Era una escuela especial de arte y pedagogía popular que funcionaba en un viejo caserón de la calle de la Esmeralda, de la cual tomó su nombre. Diego y Frida fueron llamados a formar parte del cuerpo docente, al cual pertenecían las figuras más destacadas del movimiento plástico mexicano del momento: Manuel Rodríguez, Germán Cueto, María Izquierdo, Jesús Guerrero Galván, Francisco Zúñiga, Carlos Dublán, entre otros. El sistema de la Esmeralda se caracterizaba por una total ausencia de rigidez para desarrollar al máximo la iniciativa del alumno.

Cuando Frida se hizo cargo de la cátedra de iniciación pictórica atravesaba una de sus épocas más productivas: Tehuana, Diego en mi pensamiento, la Columna rota, Pensando en la muerte, Diego y yo. Frida inició las clases en el Esmeralda con un grupo numeroso de es tudiantes atraídos por la fama y la personalidad de la artista, pero sus quebrantos de salud la obligaron a trasladar las clases a su casa de Coyoacán, un barrio bastante alejado donde el grupo quedó reducido a cuatro: Fanny Rabel, Arturo García Bustos, Guillemo Monroy y Arturo Estrada, a quienes sus contemporáneos apodaron Los Fridos. Frida fue una maestra especial que preparaba cosas de comer y refrescos para sus alumnos desde la mañana, a los que enseñaba pintura con absoluta libertad y con quienes comentaba los acontecimientos más importantes de la guerra europea y del mundo mexicano y americano del momento. 
En 1944 los maestros de la Esmeralda organizaron la primera exposición de sus alumnos en el palacio de Bellas Artes; en 1945 los Fridos, como grupo homogéneo, expusieron por iniciativa de la Escuela de Pintura y Escultura. Más tarde se unieron al grupo de Artistas Jóvenes Revolucionarios. Fue entonces cuando Frida reinició, con mucho humor y sin solemnidad académica, la pintura de las paredes externas de la pulquería Rosita, gesto que fue interpretado por muchos como el revivir de una tradición. Después vinieron los muros de los lavaderos públicos y, por último, antes de disolverse el grupo, los salones para banquetes del hotel La Posada del Sol. Diego escribió así sobre esta época de su mujer:

"Frida formó discípulos que hoy figuran entre los elementos más notables de la actual generación de artistas mexicanos. En ellos impulsó siempre la preservación y el desarrollo de la personalidad en su trabajo al mismo tiempo que la preocupación por la claridad de las ideas sociales y políticas"3.

Con el paso de los años la salud de Frida se deterioraba cada vez más obligándola a reemplazar el corsé de yeso por uno de cuero y éste por uno de acero. Los dolores de espalda hicieron necesaria una operación en la columna que, por decisión de Frida, se le realizó en Nueva York. De esta época data su cuadro Árbol de la esperanza mantente firme, que expresa ese último anhelo de recuperación y el desaliento que la empieza a embargar. Entre el año 50 y el 51 debe someterse a siete nuevas intervenciones. Frida vive en el Hospital Inglés y su cuarto poco a poco va llenándose de sus libros, cuadros, fotografías e instrumentos de trabajo. Diego decide tomar también un cuarto en el hospital, lo que le permite acompañar a su mujer en los momentos realmente difíciles. Después de un año y en silla de ruedas Frida regresa a su casa disimulando, tras un optimismo aparente, su verdadera angustia y desesperanza. Desde su silla pintó el retrato prometido al doctor Farill y empezó a mezclar alcohol y medicinas, buscando inútilmente acortar su sufrimiento.

El 13 de abril de 1953 Lola Álvarez Bravo organizó una exposición retros pectiva de la obra de Frida. La artista, desde su cama de baldaquín, trasladada a la galería, recibió el homenaje de amigos y admiradores. Después de tres mes es los médicos dieron la orden de amputarle la piema derecha. Para Frida esto era el final. Llanto, gritos, angustia y dolor ahogados en alcohol y medicinas. Diego se refugiaba en la casa de San Ángel pues no resistía ver sufrir a su mujer. Frida escribía: "Me amputaron la pierna hace seis meses; me han hecho sufrir siglos de tortura y en momentos casi perdí la 'razón'. Sigo queriendo matarme. Diego es el que me detiene, por mi vanidad que me hace pensar que le hago falta. Me lo ha dicho, yle creo pero nunca en la vida he sufrido más ... esperaré un tiempo... ${ }^{4}$

${ }^{3}$ Jamis, Rauda. Frida Kahlo. Autorretrato de una mujer. México: Edivisión, 1987. p. 267.

${ }^{4}$ Ibidem, p. 308. 
El 2 de julio de 1954, sin embargo, Frida quiso desfilar con otras 10.000 personas desde la plaza de Santo Domingo hasta el Zócalo para protestar por la caída del gobierno democrático de Jacobo Arbenz en Guatemala. Era un día lluvioso y Diego em pujaba la silla de ruedas en la que Frida, con un pañuelo arrugado en la cabeza y sin maquillaje, hacía su última presentación. El 13 fue encontrada muerta en su cama. "Embolia pulmonar" fue el dictamen de los médicos.

El cadáver de Frida, con el cabello trenzado con cintas, las manos con anillos y uno de sus trajes típicos fue velado en el palacio de Bellas Artes y luego incinerado en el crematorio civil de Dolores. Diego, como último homenaje, arrojó sobre el féretro una bandera del Partido Comunista Mexicano.

Aunque la enfermedad y la muerte de Frida dejan en Diego una profunda huella, su producción artística no se interrumpe. En 1953 inicia el mural de la fachada del Teatro Insurgentes en mosaico de vidrio, en donde narra la historia del teatro y la danza en México. Del mismo año datan su mural en tela Gloriosa Victoria y el mosaico de vidrio Baño en el río, en la casa del productor de cine, Santiago Reachi. En el 54 continúa sus murales en los corredores del Palacio Nacional y en el hospital del Seguro Social el fresco El pueblo en demanda de salud. Paradójicamente es la salud del maestro la que decae y al año siguiente se le diagnostica un cáncer.

Diego, ajeno a las recomendaciones médicas se dedica a la construcción del museo Anahuacalli, según su propio diseño, e inicia el museo a la memoria de Frida Kahlo. En agos to viaja a la Unión Soviética, para someterse a un tratamiento de cobalto, y visita Polonia y Checoeslovaquia. A su regreso se instala en Acapulco, en donde permanece la mayor parte del tiempo, no sin antes legalizar las donaciones al Anahuacalli y al museo Frida Kahlo. A finales de 1956, para celebrarle los 70 años se le rinde un homenaje nacional e intemacional. En 1957 recoge 250 obras de caballete en una importante exposición y deja inconclusos estudios y proyectos sobre la historia de México para los corredores del Palacio Nacional, sobre la independencia para el Museo Nacional de Historia y para la Escuela de Ciencias Químicas de la UNAM y sobre el cine y el teatro para el Teatro Jorge Negrete, cuando muere en la ciudad de México el 24 de noviembre de 1957. Contrariando su voluntad de ser cremado y sus cenizas mezcladas con las de Frida, fue enterrado el pintor con grandes honores en la Rotonda de los Hombres llus tres.

Aunque los críticos continúen discutiendo sobre los valores estéticos de la obra de Diego Rivera, es indudable su importancia como creador de un estilo nuevo y diferente en México, que por su temática arranca con la exaltación de una cultura prehispánica tan importante como la azteca y atraviesa las diferentes etapas de la historia nacional hasta concluir con un himno a la revolución. Por los murales desfilan personajes autóctonos y extranjeros, para cuya identificación sería necesario un exhaustivo estudio de la historia mexicana y del círculo de amistades del autor. Diego Rivera puso en marcha un movimiento cultural, nacional, revolucionario, resaltó los valores propios de su patria ylogró encontrar el lenguaje 
apropiado para expresarlos. Toda la escuela europea e italiana, es pecialmente, está reflejada en su técnica y en sus colores. Pero no sólo es importante su actitud nacionalista, sino su obra "audaz, poderosa, plena de valores estéticos, que en buena parte es producto de la fuerza creadora de un gran pueblo ${ }^{5}$.

La figura de Frida se pasea una y otra vez por los murales de Diego: en el Palacio Nacional, en la Secretaría de Educación Pública, en el cuadro-mural Firma por la Paz. Para la exposición que en 1949 el Instituto Nacional de Bellas Artes organiza para rendir homenaje a Diego Rivera por sus 50 años de labor artística, Frida escribe su conocido "Retrato de Diego":

"Advierto que este retrato de Diego lo pintaré con colores que no conozco las palabras, y por esto, será pobre; además, quiero en tal forma a Diego que no puedo ser "espectadora" de su vida, sino parte, por lo que -quizá- exageraré lo positivo de su personalidad única tratando de desvanecer lo que, aún remotamente, pueda herirlo... No hablaré de Diego como de "mi esposo", porque sería ridículo. Diego no ha sido ni será "esposo" de nadie. Tampoco como de un amante, porque él abarca mucho más allá de las limitaciones sexuales, y si hablara de él como de un hijo, no haría sino describir o pintar mi propia emoción, casi mi autorretrato, no el de Diego..."

SU FORMA: Con su cabeza asiática sobre la que nace un pelo oscuro, tan delgado y fino que parece flotar en el aire, Diego es un niño grandote, inmenso de cara amable y mirada un poco triste. Sus ojos saltones, oscuros, inteligentísimos y grandes, están difícilmente detenidos, casi fuera de las órbitas, por párpados hinchados y protuberantes como de batracio, muy separados uno del otro, más que otros ojos...

SU CONTENIDO: Diego está al margen de toda relación personal limitada y precisa. Contradictorio como todo lo que mueve en la vida, es a la vez caricia inmensa y descarga violenta de fuerzas poderosas y únicas. Se le vive dentro, como una semilla que la tierra atesora, y fuera, como a los paisajes...

Son tres las direcciones o líneas principales que yo considero básicas en su retrato: la primera, la de ser un luchador revolucionario constante, dinámico, extraordinariamente sensible y vital; trabajador infatigable en su oficio, que conoce como pocos pintores en el mundo; entusiasta fantástico de la vida y, a la vez, descontento siempre de no haber logrado saber más, construir más y pintar más. La segunda: la de ser un curioso eterno, investigador incansable de todo, y la tercera: su carencia absoluta de prejuicios y, por lo tanto, de fe, porque Diego acepta -como Montaigne- que "allí donde termina la duda comienza la estupidez", y que aquel que tiene fé en algo admite la sumisión incondicional, sin libertad de analizar o de variar el curso de los hechos... 6.

\footnotetext{
${ }^{5}$ Rodríguez, Antonio. "La obra mural de Diego Rivera" en Diego Rivera . México: INBA, 1977.

${ }^{6}$ Tibol, Raquel. Op.. cit. pp. 99-102.
} 
Seria imposible no sentir la pres encia monumental de Diego o el encanto de Frida Kahlo al recorrer una a una las habitaciones de sus casas. El puente que une el estudio de Diego en San Ángel con la parte azul de la casa hecha para Frida nos hace pensar en el puente anímico que debió existir entre estas dos extraordinarias personalidades que llenaron, con su vida y su obra, medio siglo de la vida cultural y política de México. 